\title{
An exploratory study to evaluate Clostridium difficile polymerase chain reaction ribotypes and infection outcomes
}

This article was published in the following Dove Press journal:

Infection and Drug Resistance

27 June 2016

Number of times this article has been viewed

\author{
Abrar K Thabit ${ }^{1,2}$ \\ David P Nicolau',3 \\ 'Center for Anti-Infective Research \\ and Development, Hartford Hospital, \\ Hartford, CT, USA; ${ }^{2}$ Faculty of \\ Pharmacy, King Abdulaziz University, \\ Jeddah, Saudi Arabia; ${ }^{3}$ Division of \\ Infectious Diseases, Hartford Hospital, \\ Hartford, CT, USA
}

Background: Clostridium difficile infection ranges from mild to severe prolonged diarrhea with systemic symptoms. Previous studies have assessed the correlation of some disease severity parameters to $C$. difficile ribotypes. However, certain clinical parameters of interest have not yet been evaluated.

Aim: We conducted an exploratory study to evaluate the correlation of $C$. difficile ribotypes to parameters not assessed previously, notably days to diarrhea resolution (in terms of days to formed stools and days to less than three stools per day), length of hospital stay, 30-day recurrence rates, and 30-day readmission rates. Additional severity parameters evaluated include leukocytosis, serum creatinine, fever, and nausea/vomiting.

Methods: Polymerase chain reaction ribotyping was performed on $C$. difficile isolates from baseline stool samples of 29 patients. A retrospective chart review was conducted to assess the parameters of interest.

Results: The most common ribotypes were 027 (38\%), 014/020 (21\%), and 106/174 (21\%). Numerically, 027 ribotype patients required more days to less than three stools per day versus $014 / 020$ and $106 / 174$ ribotype patients $(P=0.2)$. The three ribotypes were similar regarding time to formed stools, duration of hospitalization, and 30 -day readmission rate $(P=0.2,0.6$, and 0.8 , respectively). Recurrence within 30 days occurred in two patients with 027 and two patients with $014 / 020(P=0.6)$. Leukocytosis and fever were more prominent with 027 than with $014 / 020$ and $106 / 174$ ( $P=0.04$ for both parameters), although the degree of nausea/vomiting did not differ between the three groups $(P=0.3)$. A serum creatinine level $\geq 1.5$ times the premorbid level was seen in only three patients, each infected with a different ribotype.

Conclusion: Although these data provide a baseline assessment of outcomes to aid in the design of future studies, the diversity of $C$. difficile ribotypes within the population must be considered, and additional work with other ribotypes may further explain the association with these outcomes.

Keywords: Clostridium difficile, PCR, 027, 014/020

\section{Introduction}

Clostridium difficile infection (CDI) is the leading cause of hospital-associated diarrhea accounting for $15 \%-25 \%$ of nosocomial antibiotic-associated diarrhea, with an estimated annual US incidence of up to 453,000 cases and 29,000 deaths. ${ }^{1,2}$ Many CDI outbreaks have been reported after the identification of the common $C$. difficile strain characterized as toxinotype III, restriction endonuclease analysis group type BI, North American pulsed-field type 1 (NAP1), and polymerase chain reaction (PCR) ribotype 027 (collectively referred to as BI/NAP1/027 or more commonly 027 ). ${ }^{3}$
Correspondence: David P Nicolau Center for Anti-Infective Research and Development, Hartford Hospital, 80 Seymour Street, Hartford, CT 06I02, USA $\mathrm{Tel}+$ I 860972394 I

Fax +l 8605453992

Email david.nicolau@hhchealth.org 
The emergence of the 027 strain influenced the advancement of PCR ribotyping techniques to identify other potentially virulent strain types of $C$. difficile that might change the epidemiology of the disease. ${ }^{4,5}$ As a result, more than 200 PCR ribotypes have been described in the literature. ${ }^{6}$ Outbreaks due to 027 ribotype were mainly reported in North America, whereas $014 / 020$ was shown to be the most prevalent ribotype in Europe. ${ }^{7-10}$

The potential association of specific $C$. difficile ribotypes with the severity of infection has been assessed previously. ${ }^{11-14}$ Some of these studies focused on laboratory parameters to evaluate severity, while others looked at the disease presentation.

The current exploratory study, however, is distinguished from the previous studies as it assessed components of the disease that have not yet been studied, including time to resolution of diarrhea, length of hospital stay, 30-day recurrence rates, and 30-day readmission rates associated with each ribotype identified.

\section{Materials and methods}

\section{Patients and samples}

C. difficile isolates recovered by culture from baseline stool samples of patients experiencing their first CDI episode admitted to Hartford Hospital, Hartford, CT, USA, and enrolled in a prospective study (from October 2012 to December 2014) ${ }^{15}$ were sent for PCR ribotyping. All patients provided written informed consent prior to study enrollment (within 24 hours of CDI diagnosis), and the study protocol was approved by the Hartford Hospital Institutional Review Board (project No NICO003785HE).

\section{Isolation of $C$. difficile}

Isolation of $C$. difficile from stool samples was conducted as previously described. ${ }^{16}$ Colony-forming units grown on the cultured plates were confirmed to be of $C$. difficile using Gram staining and matrix-assisted laser desorption/ionization-time-of-flight mass spectrometry.

\section{PCR ribotyping}

Ribotyping of the clinical $C$. difficile isolates was performed using fluorescent PCR ribotyping system as previously described. ${ }^{17}$ Briefly, a fluorescent label (Integrated DNA Technologies, Inc., Coralville, IA, USA) was used in synthesizing PCR-ribotyping primers, $0.5 \mu \mathrm{L}$ forward primer (GTGCGGCTGGATCACCTCCT) and $0.5 \mu \mathrm{L}$ 6-carboxyfluorescein (FAM)-labeled reverse primer (56 FAM/CCCTGCACCCTTAATAACTTGACC) and adjusted to $10 \mathrm{pmol} / \mu \mathrm{L}$. AmpliTaq Gold DNA Polymerase (Thermo Fisher Scientific, Waltham, MA, USA) was used to conduct PCR on $25 \mu \mathrm{L}$ of the PCR product. An ABI3730xl DNA Analyzer and MapMarker 1000 ROX DNA sizing standard (BioVentures, Inc., Murfreesboro, TN, USA) were used to analyze amplicons.

\section{Data extraction}

The first day of CDI onset was defined as the day CDI symptoms started. Time to resolution of diarrhea, including time to less than three stools per day and time to formed stools, as well as length of hospital stay (starting from the date of CDI diagnosis to discharge) were extracted from patients' records. Thirty-day recurrence (defined as the presence of C. difficile along with clinical signs and symptoms of CDI after clinical cure of the initial episode) was assessed by collecting a follow-up sample 19-29 days after study enrollment and culturing it as described previously. This was followed by contacting the patients via phone 10-14 days after follow-up sample collection to ask them whether or not they developed CDI symptoms. Thirty-day readmission (after discharge date) was evaluated via chart review. Additionally, fever, presence of nausea and/or vomiting, white blood cell (WBC) count, and serum creatinine level were also assessed within 1 day of symptoms onset. A WBC count of $\geq 15,000$ cells $/ \mathrm{mL}$ and a serum creatinine level that is $\geq 1.5$ times the premorbid level were used as breakpoints to indicate disease severity. ${ }^{1,18}$ Patients exhibiting fever were assessed for other potential causes for fever, including concomitant infection or inflammatory disease. Data from patients diagnosed with CDI by PCR, but from whom $C$. difficile could not be isolated on culture, were also analyzed to eliminate any potential systemic testing bias.

\section{Data analysis}

The primary end points were time to resolution of diarrhea (time to less than three stools per day and time to formed stools in days) and length of stay (ie, time to hospital discharge in days). Secondary outcomes were elevated WBC counts, elevated serum creatinine levels, and symptoms of severity (fever and nausea/vomiting). Given that the majority of patients in this study were infected with $027,014 / 020$, or 106/174 ribotypes, statistical comparisons were conducted on these three ribotype groups. Kaplan-Meier curves for time to resolution of diarrhea and hospital discharge were constructed, and log-rank test was used for statistical comparisons between the three groups with respect to these parameters. Statistical significance was set at an $\alpha$ value of 
0.05. SigmaPlot version 12.5 (Systat Software, Inc., San Jose, CA, USA) was used to perform the analyses.

\section{Results}

\section{Patients and samples}

Twenty-nine of the 34 patients included in the initial prospective study ${ }^{15}$ had $C$. difficile in their baseline stool culture. Seven $C$. difficile PCR ribotypes were identified among this cohort. The three most prevalent ribotypes were $027,014 / 020$, and 106/174, which were seen in eleven (38\%), six (21\%), and six $(21 \%)$ of the patients, respectively. The remaining ribotypes were 001 and 002 , each found in two (7\%) of the patients, and 053/163 and 078/126 that were isolated from one patient (3\%) each. Overall, patients did not differ in their age, sex, and whether CDI was community-acquired (defined as CDI diagnosis in patients who had not been discharged from a health care facility in the previous 12 weeks) $)^{1}$ or of hospital onset ( $P>0.2$ for all comparisons).

\section{PCR ribotypes and severity of CDI}

The $C$. difficile PCR ribotypes identified and their corresponding measures of severity are shown in Table 1. Although patients infected with 106/174 ribotype had numerically shorter duration to resolution of diarrhea in terms of achieving less than three stools per day and formed stools than patients infected with 027 and 014/020 ribotypes who had approximately double the duration, these differences were not statistically significant ( $P=0.9$ and $P=0.4$, respectively) (Figure 1A and B). Likewise, the three groups did not differ with regard to length of stay until hospital discharge, as admission times in all groups ranged from as short as 1 day to as long as 13 days $(P=0.6)$ (Figure $1 C)$. Five patients of the total cohort developed CDI recurrence within 30 days of study enrollment (two with 027 ribotype, two with 014/020 ribotype, and one patient with 053/163 ribotype). When the effect of ribotype on 30-day recurrence was compared between patients infected with 027 versus those infected with 014/020, no statistical difference was noted $(P=0.6)$. When 30-day readmission was assessed in the three major groups, only three patients infected with 027 ribotype were admitted compared with one patient with $014 / 020$ and one patient with $106 / 076(P=0.8)$. In addition, one of the two patients infected with 001 ribotype and a patient from whom $C$. difficile was not isolated at baseline were readmitted within 30 days of treatment initiation.

Systemic symptoms (fever and nausea with vomiting) and leukocytosis were more prominent with 027 ribotype compared with 014/020 and 106/174 ribotypes. Potential sources of fever of infectious or inflammatory origins other than CDI were excluded by the chart review in all patients in the 027 ribotype group. One patient in the 014/020 ribotype group had fever during the CDI episode, but was diagnosed with streptococcal bacteremia. A serum creatinine level $\geq 1.5$ times the premorbid level was seen in only three patients, each infected with a different ribotype (014/020, 106/174, and $078 / 126)$.

\section{Effect of CDI therapy}

To eliminate the potential bias of the CDI therapy effect on the primary end points, we compared these outcomes in patients

Table I Identified C. difficile PCR ribotypes and corresponding parameters of disease severity (total of 34 patients)

\begin{tabular}{|c|c|c|c|c|c|c|c|c|c|}
\hline $\begin{array}{l}\text { C. difficile PCR } \\
\text { ribotype }(n)\end{array}$ & $\begin{array}{l}\text { Time to less } \\
\text { than three } \\
\text { stools per } \\
\text { day (days), } \\
\text { median } \\
{\left[{ }^{I Q R}\right]^{\mathrm{a}}}\end{array}$ & $\begin{array}{l}\text { Time to } \\
\text { formed } \\
\text { stools } \\
\text { (days), } \\
\text { median } \\
{\text { [IQR }]^{\mathrm{a}}}\end{array}$ & $\begin{array}{l}\text { Length of } \\
\text { hospital } \\
\text { stay (days), } \\
\text { median } \\
{\left[\text { IQR] }{ }^{\mathrm{a}}\right.}\end{array}$ & $\begin{array}{l}\text { 30-day } \\
\text { recurrence } \\
\text { rate, \% of } \\
\text { patients }\end{array}$ & $\begin{array}{l}30-\text { day } \\
\text { readmission } \\
\text { rate, } \% \text { of } \\
\text { patients }\end{array}$ & $\begin{array}{l}\text { White blood } \\
\text { cells count, } \\
\% \text { of patients } \\
\text { with } \geq I 5,000 \\
\text { cells/mL }\end{array}$ & $\begin{array}{l}\text { Serum } \\
\text { creatinine level, } \\
\% \text { of patients } \\
\text { with } \geq 1.5 \text { times } \\
\text { the premorbid } \\
\text { level }\end{array}$ & $\begin{array}{l}\text { Fever, } \\
\% \text { of } \\
\text { patients }\end{array}$ & $\begin{array}{l}\text { N/V, } \\
\% \text { of } \\
\text { patients }\end{array}$ \\
\hline 027 (I I) & 4 [2-7] & 5 [4-7] & 4 [3-7] & 18.18 & 27.27 & 63.63 & 0 & 54.54 & 81.8 \\
\hline $014 / 020(6)$ & $2[2-4]$ & $3[2-5]$ & $6[4-8]$ & 33.33 & 16.66 & 16.66 & 16.66 & 16.66 & 50 \\
\hline $106 / 174(6)$ & $5[5-6]$ & $6[5-6]$ & $6[3-8]$ & 0 & 16.66 & 33.33 & 0 & 0 & 50 \\
\hline $001(2)$ & $4[3-6]$ & $3.5[2-5]$ & $5[4-6]$ & 0 & 50 & 0 & 0 & 0 & 50 \\
\hline $002(2)$ & $2[1-3]$ & 5.5 [4-7] & II.5 [II-I2] & 0 & 0 & 50 & 0 & 0 & 0 \\
\hline $053 / 163(1)$ & I & 6 & II & 100 & 0 & 0 & 0 & 0 & 100 \\
\hline $078 / 126(I)$ & 2 & 5 & II & 0 & 0 & 0 & 100 & 0 & 0 \\
\hline $\begin{array}{l}\text { No isolate } \\
\text { detected on } \\
\text { culture (5) }\end{array}$ & 3 [2-5] & $6[4-7]$ & $6[3-6]$ & 0 & 20 & 20 & 40 & 0 & 40 \\
\hline
\end{tabular}

Notes: ${ }^{\mathrm{I} Q R}$ was not reported for ribotypes $053 / \mathrm{I} 63$ and 078/I 26 since only one patient was identified in each of these ribotype groups.

Abbreviations: $C$. difficile, Clostridium difficile; IQR, interquartile range; PCR, polymerase chain reaction; N/V, nausea and/or vomiting. 

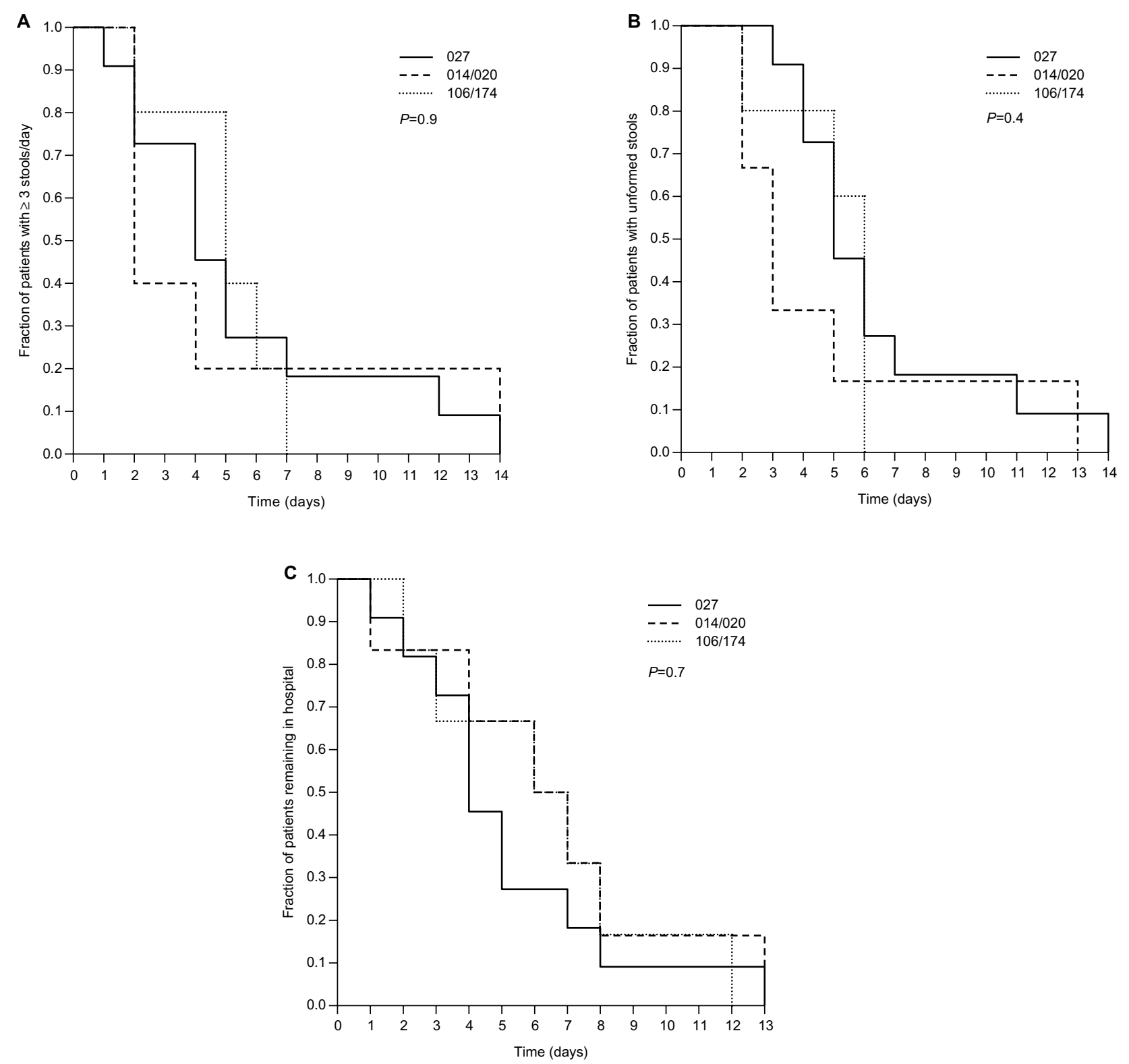

Figure I Time taken for patients with Clostridium difficile polymerase chain reaction ribotypes 027, 014/020, and 106/174 to achieve less than three stools per day (A), formed stools (B), and hospital discharge (C).

Notes: $P$-values were derived from log-rank test of Kaplan-Meier test.

who received either fidaxomicin or vancomycin (since these were the two anti-CDI agents used in the prospective study) within the three major $C$. difficile ribotype groups. In the group of patients infected with 027 ribotype, eight patients received fidaxomicin and three received vancomycin. Both the duration to less than three stools per day and duration to achieve formed stools did not differ with the anti-CDI treatment given ( $P=0.9$ and $P=0.5$, respectively); however, a significantly shorter hospital stay was seen in the fidaxomicin group versus the vancomycin group (median $=4$ versus 8 days; $P=0.02$ ). In the $014 / 020$ ribotype group, two patients were randomized to fidaxomicin and four patients were randomized to vancomycin, none of the three primary end points exhibited difference between the two treatment groups $(P>0.2$ for all comparisons). All patients in the 106/076 ribotype group were randomized to vancomycin.

\section{Discussion}

Given the remarkable increase in CDI rates globally ${ }^{2,3,19}$ and the availability of PCR ribotyping of $C$. difficile that has aided the identification of different strain types of the organism, it was prudent to attempt to classify $C$. difficile ribotypes and disease severity. In previous studies, the classification of CDI based on severity was dependent on multiple laboratory factors, including leukocytosis, serum creatinine levels, and serum albumin levels. ${ }^{1,18,20}$ Symptoms of fever, abdominal 
pain, nausea with or without vomiting, as well as terminal mortality were also included in this classification in previous studies looking at severe CDI. ${ }^{14,21,22}$ Additionally, CDIattributable admission to intensive care unit, colectomy, and ileus were also assessed in two previous studies. ${ }^{12,13}$ In the current study, however, we aimed to explore the correlation of the disease duration and CDI symptoms of severity to $C$. difficile ribotypes to assess whether an infection with a particular ribotype would predict a severe form of the disease.

The extended duration to diarrhea resolution, as well as the length of stay, was consistent among the three major ribotypes identified in this study. Although 027 ribotype was reported to be a significant factor for CDI relapse (recurrence with baseline $C$. difficile strain) but not for reinfection (recurrence with a strain different than baseline strain), ${ }^{23,24}$ only two of eleven patients $(18.18 \%)$ experienced CDI recurrence. One patient relapsed with 027 strain, whereas the other patient was reinfected with a different strain type (095). Herein, we did not find a difference between the ribotypes 027 and 014/020 and CDI recurrence. Likewise, the 30-day readmission rate did not vary among the three major ribotype groups. We did not observe a CDI therapy effect on the three primary outcomes, which indicates the lack of treatment effect bias on the results.

It has long been known that the 027 ribotype of $C$. difficile is associated with severe form of CDI ${ }^{8,25}$ This concept was evidenced in a study by Rao et al, ${ }^{13}$ who found that the identification of 027 ribotype of $C$. difficile was independently linked to severe disease, as well as mortality in hospitalized patients compared with other ribotypes. This was similar to the group of 027 ribotype patients in our patient cohort who showed signs of more severe disease. On the contrary, a study by Walk et $\mathrm{al}^{11}$ found a lack of correlation between severe CDI and different PCR ribotypes of the pathogen, including 027 ribotype. In other words, the investigators found that a high proportion of all $C$. difficile ribotypes identified were associated with severe disease. In their study, the authors focused on assessing specific laboratory parameters as well as some risk factors for CDI severity (such as age and Charlson comorbidity index) for 75 distinctly identified ribotypes. ${ }^{11}$

We should state that our study was limited with small sample size due to the complexity of the initial prospective trial from which data were extracted. In addition, as a result of the initial study methodology, we utilized PCR ribotyping to distinguish $C$. difficile ribotypes. Future studies utilizing whole genome sequencing or multiple locus variable-number tandem repeat analysis could potentially improve the yield of $C$. difficile strain population.
To our knowledge, this is the first study to evaluate the correlation of the time to diarrhea resolution and length of hospital stay as parameters of CDI severity to $C$. difficile ribotypes. Although we did not observe a difference between C. difficile ribotypes $(027,014 / 020$, and 106/174) with regard to time to diarrhea resolution and length of stay, these data provide baseline assessment of these important outcome parameters for the conduct of future larger studies.

\section{Acknowledgments}

We acknowledge Lucinda Lamb, Mary Anne Banevicius, and all staff from the Center for Anti-Infective Research and Development (CAIRD), Hartford Hospital, for their assistance with the processing of the recovered isolates. We acknowledge Kevin W Garey and M Jahangir Alam for performing the strain ribotyping.

The authors acknowledge the funding support of Cubist Pharmaceuticals (Lexington, MA, USA) for the conduct of the randomized trial comparing the microbiologic outcomes of fidaxomicin and vancomycin. This work was supported through internal funding by the CAIRD.

\section{Author contributions}

All authors were involved in the study conception, design, data collection, data analysis and interpretation, and manuscript drafting, and agree to be accountable for all aspects of the work. David P Nicolau is the guarantor of this paper.

\section{Disclosure}

The authors report no conflicts of interest in this work.

\section{References}

1. Cohen SH, Gerding DN, Johnson S, et al. Clinical practice guidelines for Clostridium difficile infection in adults: 2010 update by the society for healthcare epidemiology of America (SHEA) and the infectious diseases society of America (IDSA). Infect Control Hosp Epidemiol. 2010;31(5):431-455.

2. Lessa FC, Mu Y, Bamberg WM, et al. Burden of Clostridium difficile infection in the United States. N Engl J Med. 2015;372(9):825-834.

3. Kuijper EJ, Coignard B, Tull P. Emergence of Clostridium difficileassociated disease in North America and Europe. Clin Microbiol Infect. 2006;12(Suppl 6):2-18.

4. Freeman J, Bauer MP, Baines SD, et al. The changing epidemiology of Clostridium difficile infections. Clin Microbiol Rev. 2010;23(3):529-549.

5. Hubert B, Loo VG, Bourgault AM, et al. A portrait of the geographic dissemination of the Clostridium difficile North American pulsed-field type 1 strain and the epidemiology of $C$. difficile-associated disease in Quebec. Clin Infect Dis. 2007;44(2):238-244.

6. Tenover FC, Akerlund T, Gerding DN, et al. Comparison of strain typing results for Clostridium difficile isolates from North America. J Clin Microbiol. 2011;49(5):1831-1837. 
7. Warny M, Pepin J, Fang A, et al. Toxin production by an emerging strain of Clostridium difficile associated with outbreaks of severe disease in North America and Europe. Lancet. 2005;366(9491):1079-1084.

8. See I, Mu Y, Cohen J, et al. NAP1 strain type predicts outcomes from Clostridium difficile infection. Clin Infect Dis. 2014;58(10):1394-1400.

9. Bauer MP, Notermans DW, van Benthem BH, et al. Clostridium difficile infection in Europe: a hospital-based survey. Lancet. 2011;377(9759):63-73.

10. Pépin J, Valiquette L, Alary ME, et al. Clostridium difficile-associated diarrhea in a region of Quebec from 1991 to 2003: a changing pattern of disease severity. CMAJ. 2004;171(5):466-472.

11. Walk ST, Micic D, Jain R, et al. Clostridium difficile ribotype does not predict severe infection. Clin Infect Dis. 2012;55(12):1661-1668.

12. Aitken SL, Alam MJ, Khaleduzzuman M, et al. In the endemic setting, Clostridium difficile ribotype 027 is virulent but not hypervirulent. Infect Control Hosp Epidemiol. 2015;36(11):1318-1323.

13. Rao K, Micic D, Natarajan M, et al. Clostridium difficile ribotype 027: relationship to age, detectability of toxins A or B in stool with rapid testing, severe infection, and mortality. Clin Infect Dis. 2015;61(2):233-241.

14. Åkerlund T, Svenungsson B, Lagergren A, Burman LG. Correlation of disease severity with fecal toxin levels in patients with Clostridium difficile-associated diarrhea and distribution of PCR ribotypes and toxin yields in vitro of corresponding isolates. $J$ Clin Microbiol. 2006;44(2):353-358.

15. Housman ST, Thabit AK, Kuti JL, Quintiliani R, Nicolau DP. Assessment of Clostridium difficile burden in patients over time with first episode infection following fidaxomicin or vancomycin. Infect Control Hosp Epidemiol. 2016;37(2):215-218.

16. Housman ST, Banevicius MA, Lamb LM, Nicolau DP. Isolation and quantitation of Clostridium difficile in aqueous and fecal matter using two types of selective media. J Microbiol Immunol Infect. 2015. pii: S1684-1182.
17. Martinson JN, Broadaway S, Lohman E, et al. Evaluation of portability and cost of a fluorescent PCR ribotyping protocol for Clostridium difficile epidemiology. J Clin Microbiol. 2015;53(4):1192-1197.

18. Debast SB, Bauer MP, Kuijper EJ. European Society of Clinical Microbiology and Infectious Diseases: update of the treatment guidance document for Clostridium difficile infection. Clin Microbiol Infect. 2014;20(Suppl 2):1-26.

19. He M, Miyajima F, Roberts P, et al. Emergence and global spread of epidemic healthcare-associated Clostridium difficile. Nat Genet. 2013;45(1):109-113.

20. Bulusu M, Narayan S, Shetler K, Triadafilopoulos G. Leukocytosis as a harbinger and surrogate marker of Clostridium difficile infection in hospitalized patients with diarrhea. Am J Gastroenterol. 2000;95(11):3137-3141.

21. Zar FA, Bakkanagari SR, Moorthi KM, Davis MB. A comparison of vancomycin and metronidazole for the treatment of Clostridium difficile-associated diarrhea, stratified by disease severity. Clin Infect Dis. 2007;45(3):302-307.

22. Caroff DA, Edelstein PH, Hamilton K, Pegues DA. The Bristol stool scale and its relationship to Clostridium difficile infection. J Clin Microbiol. 2014;52(9):3437-3439.

23. Marsh JW, Arora R, Schlackman JL, Shutt KA, Curry SR, Harrison LH. Association of relapse of Clostridium difficile disease with $\mathrm{BI} /$ NAP1/027. J Clin Microbiol. 2012;50(12):4078-4082.

24. Thabit AK, Housman ST, Burnham CA, Nicolau DP. Association of healthcare exposure with acquisition of different Clostridium difficile strain types in patients with recurrent infection or colonization after clinical resolution of initial infection. J Hosp Infect. 2016;92(2): 167-172.

25. Carlson PE Jr, Walk ST, Bourgis AE, et al. The relationship between phenotype, ribotype, and clinical disease in human Clostridium difficile isolates. Anaerobe. 2013;24:109-116.
Infection and Drug Resistance

\section{Publish your work in this journal}

Infection and Drug Resistance is an international, peer-reviewed openaccess journal that focuses on the optimal treatment of infection (bacterial, fungal and viral) and the development and institution of preventive strategies to minimize the development and spread of resistance. The journal is specifically concerned with the epidemiology of antibiotic

\section{Dovepress}

resistance and the mechanisms of resistance development and diffusion in both hospitals and the community. The manuscript management system is completely online and includes a very quick and fair peerreview system, which is all easy to use. Visit http://www.dovepress.com/ testimonials.php to read real quotes from published authors. 